\title{
Design and Implementation of an Electrical Lift Controlled using PLC
}

\author{
Mohammed H. Ali \\ Electrical Power and Machines Engineering Department, Diyala University, Iraq
}

\section{Article Info}

Article history:

Received Dec 12, 2017

Revised Jan 23, 2018

Accepted Feb 11, 2018

\section{Keyword:}

DC motor

DELTA company

Elevator cabinet

Gear box

PLC

\begin{abstract}
This paper represents the possibility of controlling an electrical elevator model using PLC and studying some parameters to ensure its work, this model have been designed and constructed to perform a completed elevator work in an automating technique according to its programming and controlling method that making the connecting much more easier and safer than real relays and complicated wiring method. As well as the small DC motor drive (gear box) electrical motor that used to drive the elevator cabinet which made the transition from floor to floor much smoother and much efficient than the traditional elevators.
\end{abstract}

Copyright $\odot 2018$ Institute of Advanced Engineering and Science. All rights reserved.

Corresponding Author:

Mohammed H. Ali,

Electrical Power and Machines Engineering Department,

Diyala University,

Diyala, Baquba, 32001, mobil:+9647717218264, Iraq.

Email: moh80mmed@gmail.com

\section{INTRODUCTION}

Some of the improvements that used to achieve more quality and enhancements for the elevator systems can rewards a big difference in working lines, using reliable components to operate for years without any damage, reapplied a new programming when needed in easily way, more accuracy in running, much less time for responding and the easiness of maintenance [1].

One of the devices that offers such deals is the PLC. The PLC is a small digital computer that saves more space where while offering a lots of central processing unit work, depending on a memory and a number of inputs and outputs terminals. The ladder diagram is a type of PLC programming language based on logic functions in order to run the elevator instructions [2]-[3].

\section{WORKING PRINCIPLES}

This system represented an electrical elevator depends on some orders that received from the outside control pushbuttons and in the other hands the signals that received from the internal sensors which transmitted the instant change of elevator cabinet position as well as the elevator door case (open or close) these sensors depends on a mechanical action then changed it into an electrical signals that the PLC received it and starting to processing through the ladder logic program which it already saved in the PLC as an instructions to provide the output signals that will be responsible for moving the electrical motors of cabinet and door of elevator. this process will be described in the block diagram shown in Figure 1 [4]. 


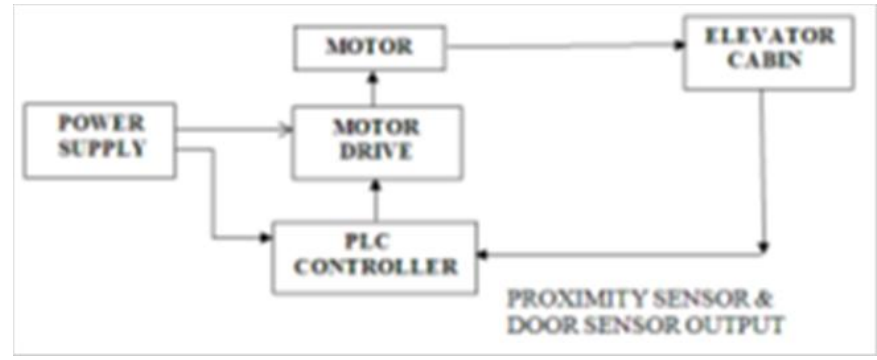

Figure 1. Electrical elevator block diagram

\section{CONSTRUCTION}

The elevator model designed to meet the required objectives of this work, such as some of a previously completed theoretical studies of a machine model that has been designed. Then to confirm and to implement the simulated model as a prototype certain calculations have been carried out to determine some critical parameters. These parameters includes the size of the cabin, maximum number of persons can be accommodated into the elevator, strength of the rope, type of motor used, motors power rating and torque rating [5].

The using of PLC in the controlling part of this system was contributed to reducing the time waste in other elevator systems, because of the electromagnetic actuators and the contact action which they have a large inertia. First of all the model build up using aluminium structure for the outer elevator body, then designing the elevator cabin by considering first of all the number of passengers, the capacity of weight and the tension of the rope[6].; all of these will be derived.

\section{ELEVATOR CONTROLLING}

The main part that is responsible on controlling this system is the PLC to overcome [7]. the difficulties of relays wiring, using DELTA PLC type, as shown in (figure-2) to perform this work which consist of $16 \mathrm{DC}$ inputs and 8 output relays.

The supply of 24 VDC is given to the PLC, the inputs used is some types of sensors beside the other pushbuttons and 2 outputs electrical motors. This elevator also includes some emergency parts such as (RUN/STOP) manual switch and the firing sensor that added into each elevator floor. All the wiring details of the PLC with the inputs and the outputs components are shown in Figure 3.

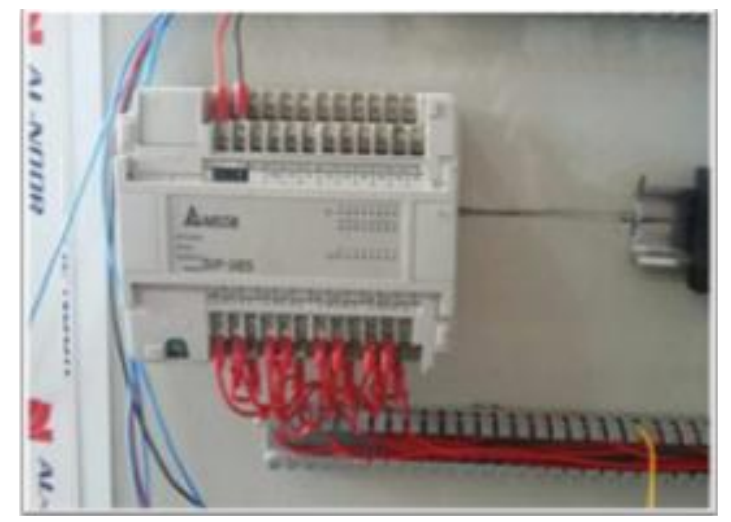

Figure 2. DELTA PLC

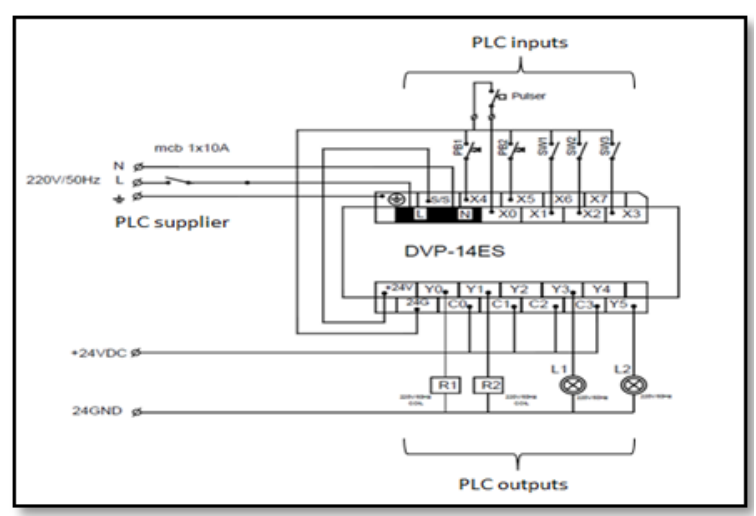

Figure 3. PLC wiring

\section{PLC INPUTS}

The PLC inputs in this system are of two types, a sensors to detect the motion and the other is a pushbutton switches type for external manual controlling[8],[9]. The sensors used to detect the elevator cabin position and the elevator door case is a magnetic sensor using LDR, as shown in Figure 4. 
Another type of sensors is used to perform a safety working which is the fire sensor, placing it in the four floors. In the other hands the pushbuttons are used to call the elevator manually or to start and stop the elevator working, also the elevator working in two cases with AC and DC voltage supply, As shown in Figure 5 and Figure 6.
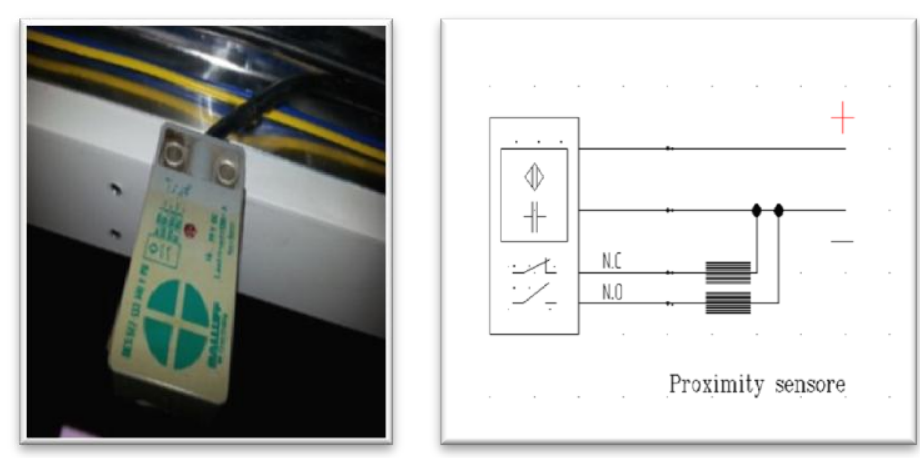

Figure 4. Proximity sensor

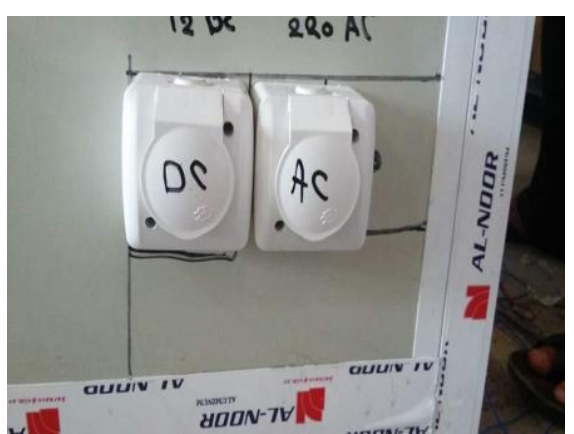

Figure 5. RUN/STOP pushbuttons

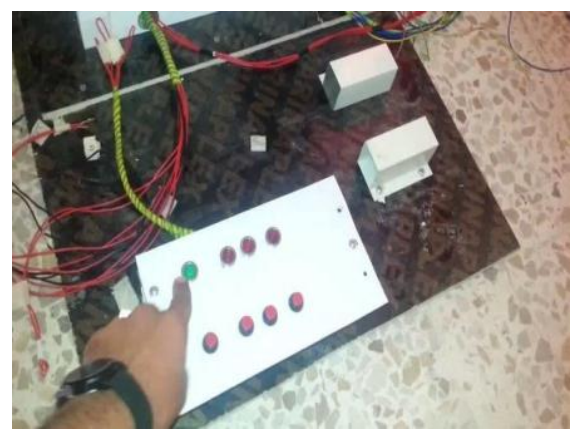

Figure 6. Call pushbuttons

The programming of the PLC represented by writing the suitable ladder logic diagram to obtain the required sequences of elevator work, the software that used to writing the ladder diagram is WPLsoft2.39, some ladder steps shown in Figure 7. Then download it to the PLC using RS232 and RS485.

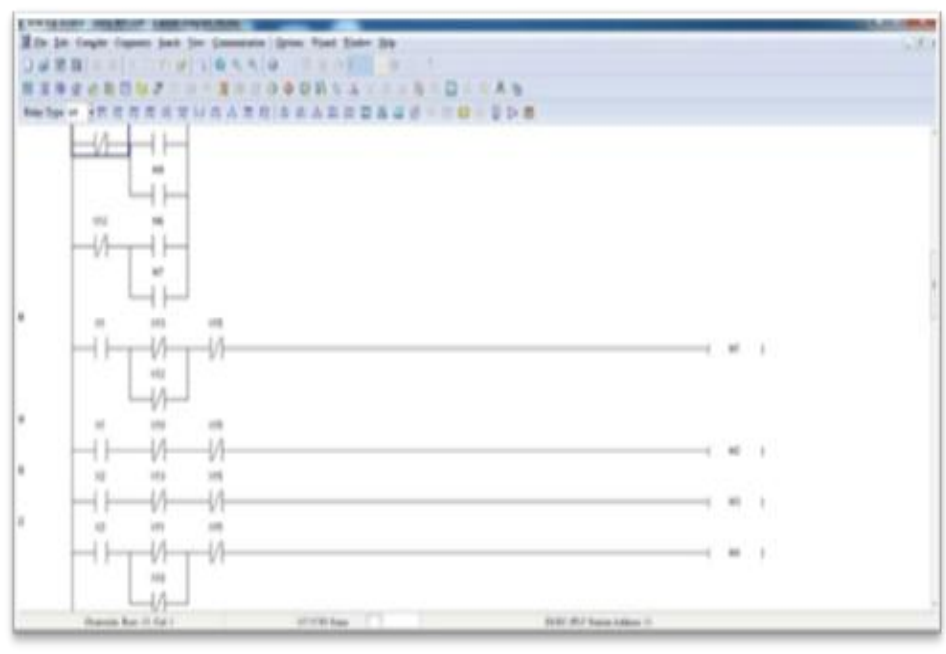

Figure 7. Ladder logic sample 


\section{MATHEMATICAL CALCULATIONS}

\subsection{Rope strength} in Table.1:

The force which acts on the rope can be found out by the following calculation, as shown

$$
F=m^{*} g
$$

Table 1. Rope Calibration

\begin{tabular}{llllllll}
\hline \multicolumn{1}{r}{ Rope Diameter } & \multicolumn{3}{c}{ Minimum braking strength } & \multicolumn{2}{c}{ Safe load } & \multicolumn{2}{c}{ Weight } \\
\hline (in) & $(\mathrm{mm})$ & $(\mathrm{ibf})$ & $(\mathrm{kN})$ & $(\mathrm{ibf})$ & $(\mathrm{KN})$ & $(\mathrm{mm})$ & $(\mathrm{ni})$ \\
\hline $1 / 4$ & 6.4 & 5480 & 24.4 & 1100 & 4.89 & 0.11 & 0.16 \\
$5 / 16$ & 8 & 8520 & 3709 & 1700 & 7.56 & 0.16 & 0.24 \\
$3 / 8$ & 9.2 & 12200 & 5403 & 2440 & $10 . .9$ & 0.24 & 0.36 \\
$7 / 16$ & 11.5 & 16540 & 7306 & 3310 & 14.7 & 0.23 & 0.48 \\
$1 / 2$ & 13 & 21400 & 95.2 & 4280 & 19.0 & 0.42 & 0.63 \\
$9 / 16$ & 14.5 & 27000 & 120 & 5400 & 24.0 & 0.53 & 0.79 \\
$5 / 8$ & 16 & 33400 & 149 & 6680 & 29.7 & 0.66 & 0.98 \\
$3 / 4$ & 19 & 47600 & 212 & 9520 & 42.3 & 0.95 & 1.41 \\
$7 / 8$ & 22 & 64400 & 286 & 12900 & 57.4 & 1.29 & 1.92 \\
1 & 26 & 83600 & 372 & 16700 & 74.3 & 1.68 & 2.5 \\
$11 / 8$ & 29 & 105200 & 468 & 21000 & 93.4 & 2.13 & 3.17 \\
$11 / 4$ & 32 & 129200 & 575 & 25800 & 115 & 2.63 & 3.91 \\
$13 / 8$ & 35 & 155400 & 691 & 31100 & 138 & 3.18 & 4.73 \\
$11 / 2$ & 38 & 184000 & 818 & 36800 & 164 & 3.78 & 5.63 \\
$15 / 8$ & 42 & 214000 & 852 & 42800 & 190 & 4.44 & 6.61 \\
$13 / 4$ & 45 & 248000 & 1100 & 49600 & 221 & 5.15 & 7.66 \\
$17 / 8$ & 48 & 282000 & 1250 & 56400 & 251 & 5.91 & 8.80 \\
2 & 52 & 320000 & 1420 & 46000 & 285 & 6.72 & 10.0 \\
\hline
\end{tabular}

\subsection{Power calculation for motor [10]}

The motor used here is a PMDC Motors through the practical experimental to determine the parameters \& characteristics for steady-state of this type of motors .In another hand the simulation approach are used by mathematical model depending on high technical were available in the computer program (MATLAB), Then the results are compared between both cases. The most important conclusions in this paper are:

a. This type of motors have Efficiency higher than Electromagnetic D.C motors.

b. The damping coefficient $(\mathrm{Bm})$ have negative effect on characteristics of motor especially at no-load steady state in spite of smallness value. The equivalent circuit for PMDC shown in Figure 8 [11].

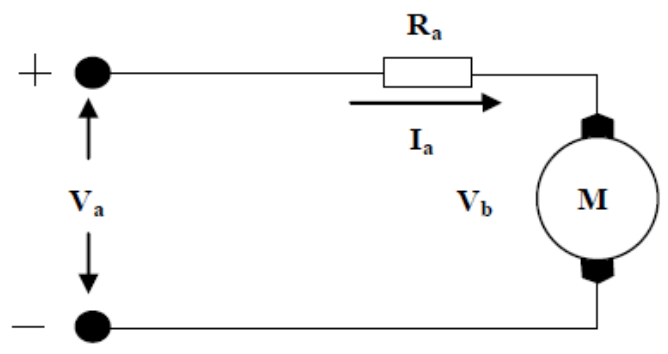

Figure 8. Equivalent circuit for PMDC

6.3. Mathematical model of DC motor drive [12]

In ideal case the mechanical power equal to electrical power

$$
\begin{aligned}
& T m * \omega m=V b * I a \\
& T m=9.55 * \frac{P o}{N}
\end{aligned}
$$




$$
\begin{aligned}
& T m * \omega m=T L * \omega L \\
& V a-E b-I a R a \\
& W=\frac{2 \pi N}{60}
\end{aligned}
$$

Where

Tm-mechanical torque $\omega m$-The angular speed of motor

Vb-the back e.m.f

Ia-armature current

Based on the design specification the output power and the output torque of the motor are calculated by a simple calculation.

Power and torque calculation.

The gear ratio 1:20

Weight of cabin $=2 \mathrm{k} . \mathrm{g} * 9.8=20 \mathrm{~N}$

$\mathrm{Ra}=0.8 \mathrm{ohm}, \mathrm{Ia}=4 \mathrm{~A}, \mathrm{Va}=12 \mathrm{~V}, \mathrm{Ea}=8.8 \mathrm{~V}, \mathrm{Fe}=0.2 \mathrm{~m} / \mathrm{s}, \mathrm{Pi}=48$ watt ,Po= 46 watt , eff $=96 \%, \mathrm{Kt}=\mathrm{Kv}=0.07$

$\mathrm{Tm}=9.55 * 46 / 1200=0.36 \mathrm{~N} . \mathrm{m}$

$\mathrm{Wm}=\mathrm{wL}=1: 20$ where $\mathrm{TL}=5.6 \mathrm{~N} . \mathrm{m}$

$\mathrm{Nm}=1200$ r.p.m

$\mathrm{NL}=60$ r,p.m

$\mathrm{Wm}=125.6 \mathrm{rad} / \mathrm{sec}$

$\mathrm{wL}=6.28 \mathrm{rad} / \mathrm{sec}$

\section{WIRING OF THE PROJECT}

By using CADdy++ program designer the electrical circuits were design and connected with software form to achieve an completed design before connecting it on the real system as in Figure 9 (a), and Figure 9 (b).

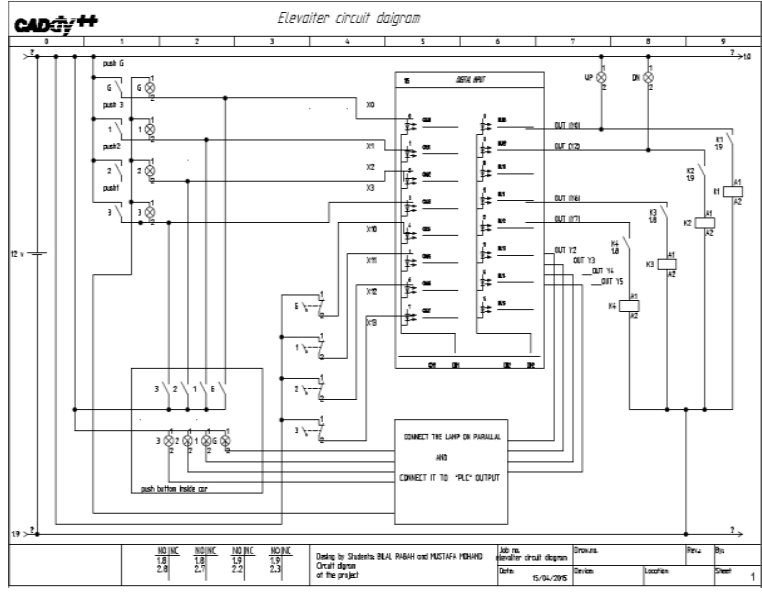

(a)

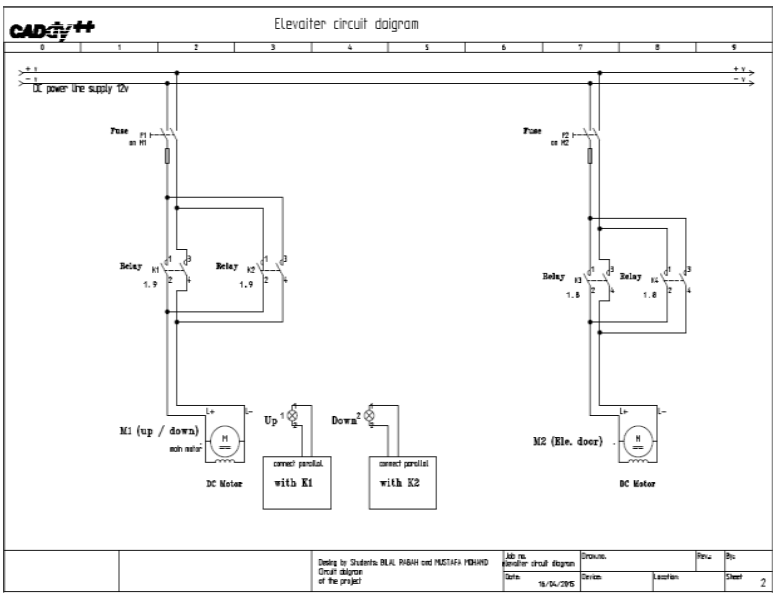

(b)

Figure 9. (a) Electrical circuit design (control circuit), (b) Electrical circuit design (power circuit)

\section{FUTURE WORK}

The researcher will be able to choose this work as a beginning for a complex controlling systems, in the other hand it can be able to use the mathematical calculations of this system as a guide to another work. 
Also the adding of another PLC to control a more level elevator is possible as well as controlling another elevator by the same PLC at the same time.

\section{RESULT AND DISCUSSION}

In this work an enhancements have been done on the previous models available [1], [2], [4]. More options are available, new Ventilation system and smart technic DELTA PLC has been proposed.

\section{CONCLUSION}

In this paper the developed design and implementation of the electrical elevator controlled using PLC was studied and discussed. The model includes a ladder logic diagram for running the entire operation of the elevator and some emergency specifications that added a new features to the system. Also adding some suggestions to explain how to develop this elevator in different ways. Finally, it's clear that is the using of DELTA PLC to controlling such systems is a good issue that will be affordable to the industrial world. The model of the design and implementation of left shown in Figure 10.
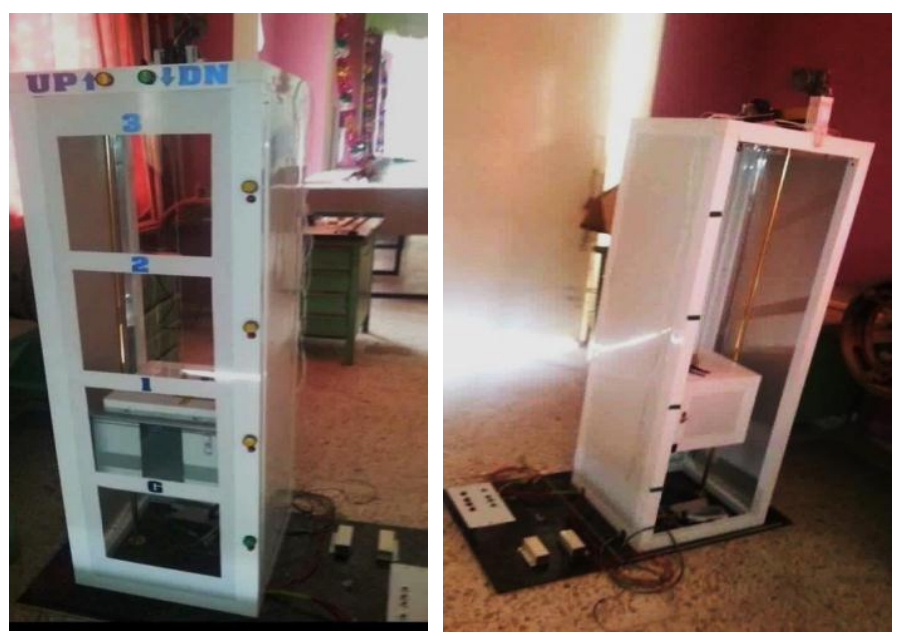

Figure 10. The design and implementation of lift model

\section{REFERENCES}

[1] Eunsoo Jung, Hyunjae Yoo, Seung-Ki Sul, Hong-Soon Choi and Yun-Young Choi, (2012), “A Nine-Phase Permanent-Magnet Motor Drive System for an Ultrahigh-Speed Elevator", IEEE Transactions on Industry Application, vol. 48, pp. 987-995.

[2] H.P. Jayawardana A.P, Amarasekara. H.W.K.M., Peelikumbura. P.T.S., Jayathilaka. W.A.K.C., Abeyaratne.S.G. and S.D Dewasurendra, (2011), "Design and implementation of a statechart based recon Figureurable elevator controller", 6th IEEE International Industrial and Information Systems, IEEE Conference Publications, vol. 10 , no. 2 , pp. 352-357.

[3] Jiang Jing and Zhang Xuesong, (2011), "Variable frequency speed-regulation system of elevator using PLC technology", 3rd International Conference on Advanced Computer Control, IEEE Conference Publications, pp. 328-332.

[4] B Knezevic, B. Blanusa and D. Marcetic, (2011), "Model of elevator drive with jerk control", XXIII International Symposium on Information, Communication and Automation Technologies, IEEE Conference Publications, pp. 1-5.

[5] Ma Yinyuan and Jiang Zhaoyuan, (2010), "Task-Oriented Analysis and Design Method for Developing PLC Programs for Mechanical System Control”, International Conference on Measuring Technology and Mechatronics Automation, IEEE Conference Publications, vol. 3, pp. 726-729.

[6] A Onat, E Kazan ,Takahashi. N, Miyagi D, Komatsu Y and Markon S, (2010), "Design andImplementation of a Linear Motor for Multicar Elevators”, IEEE/ASME Transactions on Mechatronics, vol. 15, pp. 685-693.

[7] Peng Wang (2011) 'A Control System Design for Hand Elevator Based on PLC'IEEE Conference Publications, vol. 1, pp 77-74.

[8] Chakraborty, K., Roy, I., De, P. and Das, S., 2015, "Controlling the Filling and Capping Operation of a Bottling Plant using PLC and SCADA", Indonesian Journal of Electrical Engineering and Informatics (IJEEI), vol. 3, no. 1 , pp. 39-44. 
[9] Soetedjo, A., Nakhoda, Y. I., Lomi, A and Farhan, F., (2014), "Web-SCADA for Monitoring and Controlling Hybrid Wind-PV Power System", TELKOMNIKA (Telecommunication Computing Electronics and Control), vol. 12, no. 2, pp. 305-314.

[10] Srinivasan, K., Vijayan, S., Paramasivam, S. and Sundaramoorthi, K., (2016), "Power Quality Analysis of Vienna Rectifier for BLDC motor Drive Application”, International Journal of Power Electronics and Drive Systems, vol. 7, no. 1, p.7.

[11] A.C., Vidanapathirana. S. D. Dewasurendra and S.G Abeyratne, (2011), "Statechart based modeling and controller implementation of complex reactive systems", 6th IEEE International Conference on Industrial and Information Systems, pp. 493-498.

[12] Wang Feng and He Fengyou, (2010), "Study of Hoist Perception System Based on IOT Technology", International Conference on Web Information Systems and Mining, IEEE Conference Publications, pp. 357-360. 